\title{
Enzyme Immunoassays for Anti-Hepatitis C Virus Antibodies Improved Specificity and Analytical Sensitivity by Combination of Three Different Recombinant Viral Proteins in Second Generation Tests ${ }^{1}$ )
}

\author{
By W. Prohaska ${ }^{1}$, E. Schroeter ${ }^{2}$, Petra Kaars-Wiele ${ }^{2}$ and K. Kleesiek ${ }^{1}$ \\ ${ }^{1}$ Institut für Laboratoriums- und Transfusionsmedizin, Herzzentrum Nordrhein-Westfalen, Universitätsklinik \\ der Ruhr-Universität Bochum, Bad Oeynhausen \\ ${ }^{2}$ Abbott GmbH Diagnostica, Wissenschaftliche Abteilung, Wiesbaden-Delkenheim
}

(Received November 27, 1991/April 3, 1992)

\begin{abstract}
Summary: The detection of hepatitis C virus infection currently relies on a "virology without a virus" approach. So far, only viral nucleic acid has been isolated and sequenced by the methods of genetic engineering. The resulting viral sequence was then used to "design" proteins for diagnostic use as antigens in enzyme immunoassays (EIA).
\end{abstract}

A first-generation EIA (EIA I), which uses a non-structural hepatitis $\mathrm{C}$ virus protein as antigen, detected 26 $(0.6 \%)$ reactive sera out of a total of 4350 blood donors. An inhibition test using recombinant hepatitis C virus antigen, and EIAs using other, both synthetic and recombinant hepatitis $\mathrm{C}$ virus peptides were used as a specificity enhancing measure and as confirmatory tests, respectively. Only 7 of these reactives $(0.16 \%$, inhibition test) and $5(0.11 \%$, peptide EIA) were confirmed positive. Of the 26 initially reactive donor sera, 5 sera $(0.11 \%)$ reacted positive in a second-generation anti-hepatitis $\mathrm{C}$ virus antibody EIA (EIA II), which uses two different recombinant non-structural hepatitis $\mathrm{C}$ virus proteins and one recombinant core protein.

Seventeen (77\%) of 22 haemophiliacs reacted positive in EIA I, and $19(86 \%)$ did so in EIA II. There were no false positives in this cohort.

Twenty-eight (19\%) out of 148 liver disease patients showed a positive reaction in EIA I, and $31(21 \%)$ were reactive in EIA II. Based on the results of the peptide enzyme immunoassay, 1 serum of this group was false positive in EIA I, while none of the sera of this group were false positive in EIA II.

Parallel testing of 42 anti-hepatitis $C$ virus-positive sera in geometric serial dilutions gave a median titre of 71.8 for the triple-antigen assay (EIA II) versus a median titre of only 17.4 for the single-antigen test (EIA I).

In four out of eight sera exclusively positive in EIA II, the presence of antibodies to epitopes not used in EIA I was demonstrated by enzyme immunoassays with defined hepatitis $C$ virus peptides.

In conclusion, the analytical sensitivity of EIA II is greater than that of EIA I. In conjunction with its better specificity (improved positive predictive value), as clearly demonstrated in a low-prevalence cohort of blood donors, the three antigen EIA (EIA II) offers considerable diagnostic progress.

\footnotetext{
1) Some of the results of this study were presented at the Annual Meeting of the Deutsche Gesellschaft für Klinische Chemie in Nuremberg, Germany, in October, 1991.
} 


\section{Introduction}

Non-A, non-B hepatitis not only accounts for as many as $80-90$ percent of all cases of posttransfusion hepatitis but is indeed the most frequent of all infectious complications of blood transfusions (for a review see 1.c. (1)).

The causative virus of most of these cases of hepatitis, now called hepatitis $C$ virus, was discovered as recently as 1988 by molecular biology methods (2). Soon afterwards, the same team developed a test that was capable of detecting antibodies to a fusion protein of human superoxide dismutase and a viral gene product (polypeptide C100-3, consisting of 527 amino acids) (3). This protein, which is used for coating reactive surfaces for enzyme immunoassays (EIAs), was expressed in yeast by genetic engineering methods. Apart from the immunogenic moiety of hepatitis $\mathrm{C}$ virus polypeptide $\mathrm{C} 100$ (363 amino acids), this fusion protein also contains linker sequences and, for enhanced expression, 154 amino acids of human superoxide dismutase $(3,4)$. This test system (3) causes positive reactions in about 80 percent of all patients who acquired non-A,non-B hepatitis via blood or blood products $(3,5-8)$. Haemophiliacs, who had been high-risk patients for all infections transmissible through blood products, are reactive for anti-hepatitis $\mathrm{C}$ virus antibody in this enzyme immunoassay in $60-$ 80 percent of cases $(9,10)$. The prevalence of antihepatitis $\mathrm{C}$ virus antibody in blood donors is significantly lower, typically less than 1 percent $(11-13$, 16).

Of central interest to transfusion medicine is the extent to which reactivity in the EIA described above is correlated with the infectiousness of reactive blood donations.

The reverse transcriptase and polymerase chain reaction combination detected viral nucleic acid in almost all specifically antibody positive donor sera (14). Earlier investigations demonstrated that the percentage of initially C100-3 antibody-positive blood donations that transmitted hepatitis $C$ virus infections to recipients $(16,17)$ was essentially identical with the more recently determinable percentage of confirmed EIA positive sera $(14,15,30)$.

As the polymerase chain reaction is - at least for the time being - not a feasible approach' to blood donor screening, improvement in the specificity and sensitivity of available enzyme immunological methods is a central concern.

\section{Materials and Methods}

Test sera

We analysed sera from 4350 blood donors at the Herzzentrum Nordrhein-Westfalen, Germany, whose donations had been screened for hepatitis $\mathrm{C}$ virus antibodies. In addition, we used sera from a cohort of 22 haemophiliacs (17 with haemophilia A, 5 with haemophilia B), as well as 148 sera from patients with liver disease. Nineteen of the haemophiliac patients had been treated with non-virus inactivated plasma products before 1985. The sera from cases of liver disease originated from patients for whom the treating physician had requested the determination of the anti-hepatitis $C$ virus antibody status for evaluation of the cause of the liver disease.

First-generation, single antigen anti-hepatitis $C$ virus enzyme immunoassay

The EIA was performed exactly as specified in the manufacturer's (Abbott, Wiesbaden, Germany) assay procedure. The anti-hepatitis $\mathrm{C}$ virus EIA is based on the following principle: C100-3 fusion protein isolated and purified from yeast cells is bound to a reactive surface. In the first incubation step, antibody present in the $1: 40$ diluted sample reacts with the solid phase bound antigen. After a wash procedure, peroxidaseconjugated anti-human IgG is added. The resulting "sandwich" structure can be detected spectrophotometrically at $490 \mathrm{~nm}$ by conversion of the substrate, $o$-phenylenediamine. For reading results, a cutoff is calculated from the mean of the absorbances of the negative controls plus $25 \%$ of the mean of the absorbances of positive controls. Samples showing an absorbance greater than the cutoff were considered EIA positive.

To obtain a measure of the antibody concentrations in the EIApositive samples, geometric serial dilutions of these samples were prepared with pooled anti-hepatitis $C$ virus-negative (in EIA II) serum, thus enabling the determination of the greatest above-cutoff dilution (titre).

Second-generation, triple recombinant antigen antihepatitis $C$ virus enzyme immunoassay

The assay procedure of the second-generation, three recombinant antigen anti-hepatitis $C$ virus enzyme immunoassay (EIA II) (Abbott, Wiesbaden, Germany) is essentially identical with that of the first-generation enzyme immunoassay (EIA I); for details see above. The solid phase (bead surface) of EIA II is coated with three distinct recombinant antigens, $\mathrm{C} 100,33 \mathrm{c}$, and the core antigen. To scavenge non-specifically reacting antibodies, the sample diluent contains a lysate of $E$. coli and yeasts, as well as soluble superoxide dismutase.

Defined hepatitis $C$ virus peptide antigen confirmatory enzyme immunoassay

The assay procedure of this type of EIA is essentially identical with that of EIA I (see above). Beads coated with peptides sp65/67, sp 75, and 33c are used as the solid phase. While sp75 is a core peptide, sp65/67 and 33c are derived from the nonstructural portion of the hepatitis $\mathrm{C}$ virus genome. Peptides sp67/67 and sp75 are fully synthetic, while antigen $33 \mathrm{c}$ is recombinant (all from Abbott, Wiesbaden, Germany). Figure 1 shows the assignment of these peptides to the hepatitis $C$ virus genome. All sera reacting in the first-and/or second-generation enzyme immunoassays were tested with peptide EIA. 
1 Amino acids

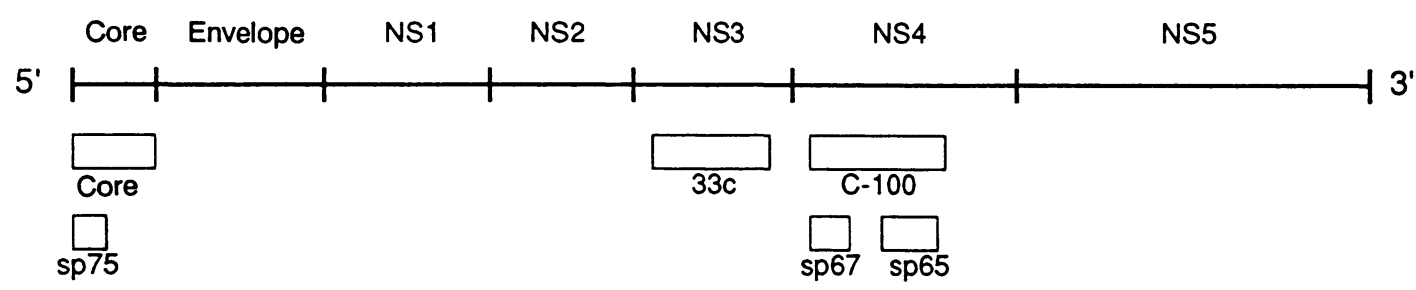

Fig. 1. Position in the hepatitis $C$ virus genome and size of five hepatitis $C$ virus peptides used in enzyme immunoassays (from 1.c. (31), modified).

NS 1 to NS 5:

EIA 1st generation:

EIA 2nd generation:

Peptide EIA's:

non-structural proteins

$\mathrm{C} 100$

core, $33 \mathrm{c}, \mathrm{C} 100$

using either sp65/67, sp75 or $33 \mathrm{c}$
Hepatitis $C$ virus inhibition test (neutralization test)

A neutralization test using a soluble, highly purified recombinant hepatitis $C$ virus antigen (Abbott, Wiesbaden, Germany) (a partial sequence of the $\mathrm{c100}$ antigen) was used as a specificity enhancing measure in all EIA-positive samples. This recombinant hepatitis $C$ virus antigen consists of 256 of the 363 amino acids of hepatitis $C$ virus protein C100 (21). Sample antibodies specifically directed against the hepatitis $C$ virus antigen can be neutralized by the soluble antigen via immune complex formation, i.e. it is no longer available for sandwiching in a subsequent EIA. As a result, the absorbance of specifically neutralized samples is significantly lower than that of the control. Two aliquots $(100 \mu \mathrm{l})$ of sample were each diluted $1: 40$ with neutralization reagent and incubated at $40{ }^{\circ} \mathrm{C}$ for $30 \mathrm{~min}$ utes for further antibody neutralization. Another two aliquots were diluted 1:40 in sample diluent (yeast extract plus bovine serum and goat serum) and used as controls. After neutralization, a C100 antigen-coated bead of the EIA was added, and the assay continued as for screening. A sample was considered specifically neutralizable and hence positive if the absorbance of the neutralized aliquots was less than 50 percent of the absorbance of the controls. To demonstrate the inhibition effect, geometric serial dilutions of the recombinant antigen solution (initial concentration $160 \mathrm{mg} / \mathrm{l}$ ) were prepared with sample diluent. The inhibition solutions of different concentrations were used to preincubate 5 specifically anti-hepatitis $C$ virus positive sera.

Determination of the detection limits of the one- and three-antigen EIAs

The analytical sensitivity of the single- and triple-antigen EIAs was determined in 42 sera that were positive in the inhibition test, and which originated from liver disease patients, haemophiliacs, and blood donors. Pooled anti-hepatitis $\mathrm{C}$ virus-negative (EIA II) blood donor sera were used to prepare geometric serial dilutions. The greatest dilution that still gave a positive reaction was reported as the titre.

\section{Other tests}

The alanine aminotransferase was determined by the optimized standard method of the Deutsche Gesellschaft für Klinische Chemie (assay temperature: $25^{\circ} \mathrm{C}$ ). The upper limit of the reference range for blood donors in our laboratory is $25 \mathrm{U} / \mathrm{l}$.

\section{Statistical methods}

Given that the titres showed an approximately log-normal distribution, we calculated the median and spread. The logarithms of the titres were used for setting up the linear regression curve. The signed rank test for non-parametric comparison of paired samples was used to analyse the significance of the differences between the detection limits of two enzyme immunoassays.

\section{Results}

Of the 4350 blood donors studied by us, 26 were reactive in the first-generation enzyme immunoassay (EIA I). In the group of 281 blood donors with elevated alanine aminotransferase, one serum was positive in EIA I (tab. 1). All sera reacting positive in EIA I were analysed by the inhibition test for enhanced specificity, including those from haemophiliacs and liver disease patients. In order to characterize the inhibition test we retested five highly positive sera in the EIA at various dilutions of the inhibition antigen. This dilution experiment revealed that the inhibition antigen was present in more than 10 -fold excess (fig. 2).

All EIA I positive haemophiliacs (17/17) were positive in the inhibition test, and all had been treated with non-virus-inactivated plasma products in the pre AIDS era. Twenty-three of the $28(82 \%)$ liver disease patients who were reactive in EIA I gave a positive inhibition test. Only $27 \%(7 / 26)$ of the blood donors were positive in the inhibition test (tab. 1). The differences between the three cohorts are statistically significant in the $\chi^{2}$-test $(p<0.01)$. The triple-antigen EIA II was used in a subcohort of $n=1000$ blood donors. Three reacted positively in EIA II and one of these reactive sera did not show a positive reaction in EIA I. In the same subcohort, 9 sera were reactive in EIA I, only 2 of which were positive in the peptide enzyme immunoassay and inhibition test. 


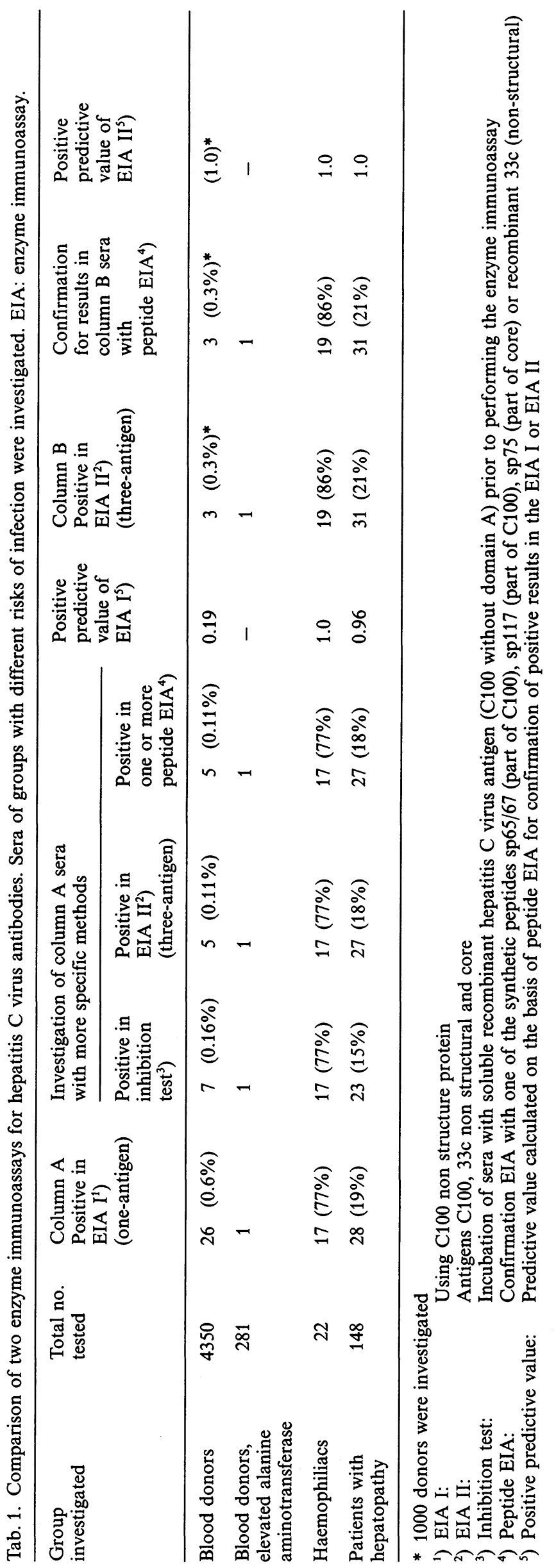

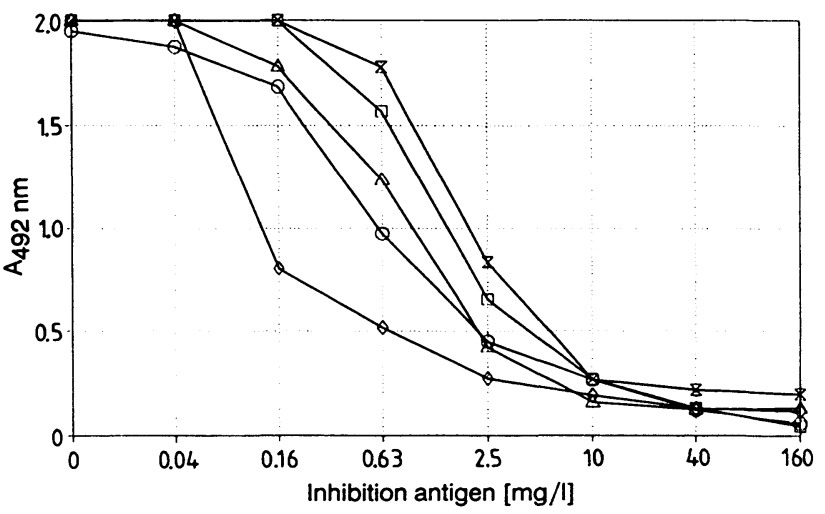

Fig. 2. Influence of various concentrations of the recombinant inhibition antigen on the absorbance of the enzyme immunoassay.

The curves of five specifically hepatitis $C$ virus antibody positive sera are shown.

The concentration of the inhibition antigen was 160 $\mathrm{mg} / \mathrm{l}$.

Nineteen of the 22 haemophiliac sera were reactive in EIA II, including two sera that were not reactive in EIA I. A similar trend emerged for the liver disease patients: all but one of the 28 sera that reacted positively in the first-generation enzyme immunoassay were also reactive in EIA II. The one serum positive in EIA I but negative in EIA II gave a negative inhibition test. Twenty-three out of $28(82 \%)$ were positive in the inhibition test. In addition, there were 3 sera that were reactive in EIA II only (tab. 1).

Of the 26 blood donors with a positive reaction in EIA I, only 5 were reactive in EIA II (predictive value of EIA I: 0.19 in tab. 1). The positive predictive value of a reactive one-antigen EIA is therefore low. It can be improved considerably by an additional inhibition test (tab. 1).

Eight sera of all cohorts tested by us had a positive EIA II, but gave a negative result in EIA I. These inconsistently reacting sera, which suggest a greater sensitivity of the EIA II, were retested by defined short-chain hepatitis $C$ virus peptide EIAs. Four of these sera showed positive reactions with peptides sp65/67, which are fragments of the $\mathrm{C} 100$ antigen (fig. 1 and tab. 2). Another two sera did not react in the EIA with sp65/67 or sp75, but they did react with non-C100-overlapping peptide 33c (fig. 1 and tab. 2).

Figure 3 compares the analytical sensitivities of the enzyme immunoassays by parallel determinations of the highest dilution in anti-hepatitis $C$ virus negative (EIA II) serum which still gives a positive reaction in a given EIA. All but one out of the 42 tested sera showed a higher titre in EIA II (fig. 3). The median serum titre of the first-generation EIA was 17.4 versus 71.8 for the second-generation EIA. 
Tab. 2. Reactivity in peptide enzyme immunoassays for confirmation of 8 sera which reacted positive in the second generation (triple antigen) enzyme immunoassay while being negative in the first generation (one antigen) hepatitis $\mathrm{C}$ enzyme immunoassay.

EIA 1st: first generation anti-hepatitis $C$ enzyme immunoassay

EIA 2nd: second generation anti-hepatitis $C$ enzyme immunoassay

Sp65/67, 33c: hepatitis $C$ virus non-structural peptides

A: $\quad$ absorbance of sera investigated

$\mathrm{A}_{c o}$ : absorbance calculated for cut off

\begin{tabular}{|c|c|c|c|c|c|}
\hline \multirow{2}{*}{ Serum code } & \multicolumn{2}{|c|}{ Screening EIA } & \multicolumn{3}{|c|}{ Peptide EIA for confirmation } \\
\hline & $\begin{array}{l}\text { EIA 1st } \\
\text { A/A }_{\infty}\end{array}$ & $\begin{array}{l}\text { EIA 2nd } \\
\mathrm{A} / \mathrm{A}_{\mathrm{co}}\end{array}$ & $\begin{array}{l}\text { sp65/67 } \\
\mathrm{A} / \mathrm{A}_{\mathrm{co}}\end{array}$ & $\begin{array}{l}\text { sp75 } \\
A / A_{c o}\end{array}$ & $\begin{array}{l}33 c \\
A / A_{\infty}\end{array}$ \\
\hline 1 & 0.4 & 4.0 & 1.15 & 1.86 & - \\
\hline 2 & 0.3 & 4.2 & 1.28 & 3.9 & - \\
\hline 3 & 0.7 & 3.3 & 2.19 & 4.2 & - \\
\hline 4 & 9.7 & 1.4 & 0.27 & 1.2 & - \\
\hline 5 & 0.3 & 1.0 & 0.56 & 3.63 & - \\
\hline 6 & 0.4 & 3.3 & 0.68 & 0.33 & 4.66 \\
\hline 7 & 0.2 & 2.2 & 0.61 & 0.36 & 2.54 \\
\hline 8 & 0.5 & 3.5 & 1.90 & $>4.2$ & - \\
\hline
\end{tabular}

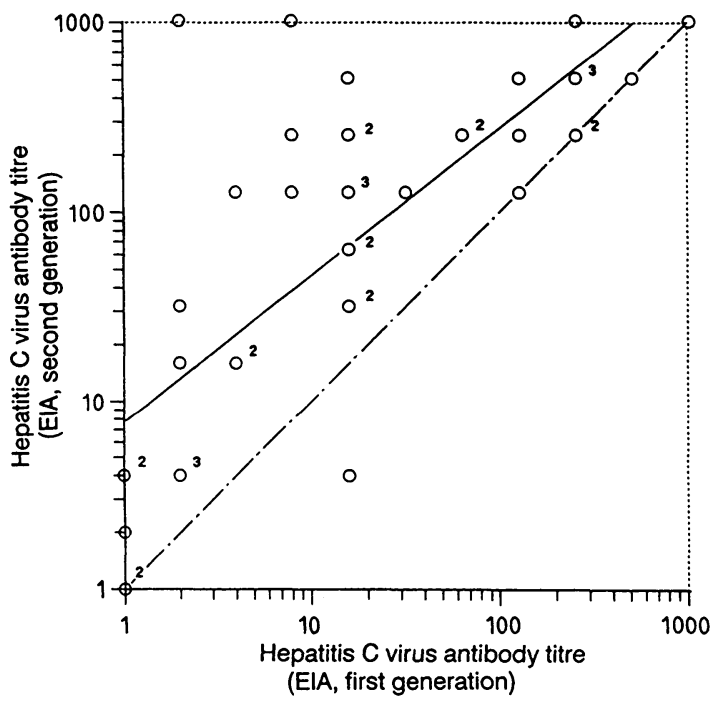

Fig. 3. Analytical sensitivity of anti-hepatitis $C$ virus enzyme immunoassay. The titres of 42 sera were simultaneously determined in the first generation (one antigen) and the second generation (triple antigen) enzyme immunoassays (EIA's).

Titres:

EIA first generation $\quad(n=42): 17.4$ (median)

EIA second generation $(n=42)$ : 71.8 (median)

Figure 4 illustrates the relationship between the absorbance of undiluted serum in the EIA at $490 \mathrm{~nm}$ and the resulting titre of 42 samples that were reactive in both EIAs. Tested by EIA I, most of the undiluted samples showed an absorbance of greater than 2.0, which corresponds to a titre of $1: 16$ to $1: 1024$. Low titres show a moderate correlation with absorbance. EIA II-positive samples show a better absorbancetitre correlation. Thus, figure 4 shows a clearly different $\mathrm{A} / \mathrm{A}$ cutoff titre relationship for the subset of reactive EIA II tests.

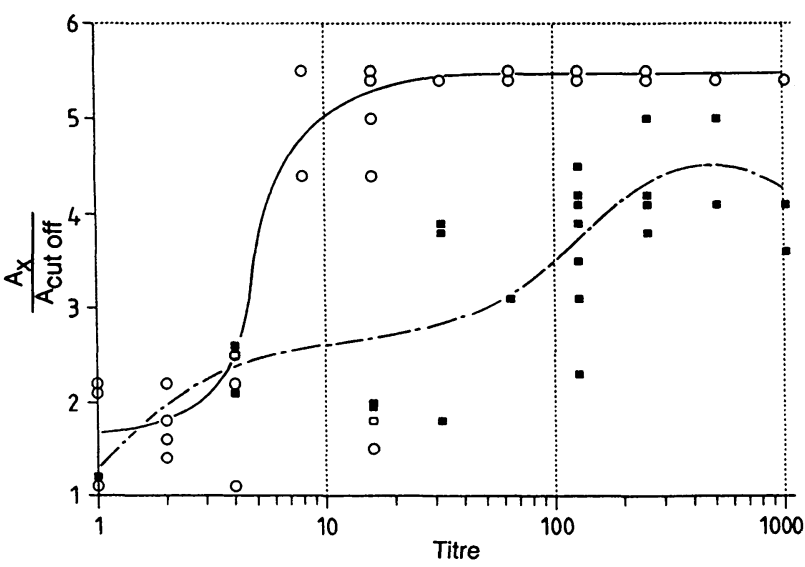

Fig. 4. Correlation between the hepatitis $C$ virus antibody concentration (titre) in serum and the absorbance reading of two anti-hepatitis $C$ virus enzyme immunoassays. ०-०: $\quad$ First generation (one antigen) anti-hepatitis $C$ virus enzyme immunoassay

- - - $\mathbf{n}$ : Second generation (triple antigen) anti-hepatitis $C$ virus enzyme immunoassay

$A_{x} / A_{\text {cut orf: }}$ ratio of absorbance of a particular serum sample to the calculated absorbance of the cut off value

\section{Discussion}

Since the first report in 1989 (3) of an enzyme immunoassay that gives positive reactions in the majority of patients with non-A, non-B hepatitis, this EIA has been used widely all over the world. In Germany, for instance, all blood banks perform an anti-hepatitis $\mathrm{C}$ virus screening. Worldwide prevalences (for a review see 1.c. (4)) are reported to range between 0.4 and 1.4 percent, as determined by first-generation enzyme immunoassay (EIA I, C100 antigen). The objective of further investigations was to determine 
the percentage of EIA-reactive blood products that had caused hepatitis in the recipient or tested positive for hepatitis $\mathrm{C}$ virus nucleic acid by reverse transcription and polymerase chain reaction. The percentage of blood products affected in this way ranged from 15 to 25 percent $(16,17,14)$. The resulting percentage of infectious sera among hepatitis $C$ virus antibody positive sera appears quite small and is indeed considerably larger, when the 70 percent false positives of EIA I (recombinant C100 antigen) in blood donors $(15,14,22)$ are excluded. Since there is a close correlation between potential infectiousness, as demonstrated by the polymerase chain reaction, and the detection of anti-hypatitis $C$ virus antibodies $(14,23)$, and since the polymerase chain reaction is as yet not suitable for routine screening, the development of a sensitive and specific immunologic method for hepatitis $\mathrm{C}$ virus antibody detection is a prime diagnostic concern.

We therefore analysed our cohort of 4350 blood donors and obtained $n=26(0.6 \%)$ reactive sera in EIA I (recombinant C100 antigen). In 281 blood donor sera with elevated alanine aminotransferase $(>25$ $\mathrm{U} / \mathrm{l})$ there was one anti-hepatitis $C$ virus positive serum, showing that the prevalence is no higher in this surrogate marker positive subgroup (tab. 1). Retesting of the 26 EIA I reactive sera by the secondgeneration enzyme immunoassay (three distinct solid phase bound hepatitis $C$ virus antigens) yielded merely 5 reactive sera ( 81 percent false positives). The inhibition test and peptide enzyme immunoassay gave similiar results (tab. 1). It is important that all EIA II positive sera were confirmed positive by peptide enzyme immunoassay (tab. 1).

The percentage of false positives by EIA I is significantly lower in groups of haemophiliacs, who are at a much higher risk of hepatitis $C$ virus infection, and in liver disease patients (tab. 1). In a cohort of 22 haemophilia patients, 17 had confirmed hepatitis $\mathrm{C}$ virus antibodies. All of the latter patients had been treated with non-virus-inactivated plasma products in the pre AIDS era. The positive predictive value of a first-generation enzyme immunoassay (C100 antigen only) is high $(>0.8)$ in groups at high risk of hepatitis $\mathrm{C}$ infection. In blood donor, i. e. low risk populations, on the other hand, the positive predictive value is as low as $0.2-0.3$ (tab. 1). Thus, particularly in this group, a positive test result has to be interpreted with great caution.

The positive predictive value of an anti-hepatitis $C$ virus antibody enzyme immunoassay for blood donor screening was improved significantly by the use of second-generation EIA, at the same time enhancing the diagnostic sensitivity of the test. Thus, in a subcohort of $n=1000$ blood donors tested by us, we obtained 9 reactive sera in EIA I and 3 reactive sera in EIA II; one of the latter 3 had not been detected by EIA I (data not shown). In the liver disease and haemophiliac cohorts, there was also a small number of sera that reacted positive in the second-generation enzyme immunoassay only, thus indicating a greater diagnostic sensitivity of this new EIA (tab. 1).

These EIA I false negatives were retested by additional enzyme immunoassays using defined short protein sequences of the hepatitis $C$ virus polyprotein (fig. 1). Four of these 8 sera showed positive reactions with peptides sp65/67. These peptides are fragments of the C100-3 antigen used in EIA I, which would therefore have been expected to be reactive as well. Failure of EIA I to give positive reactions in these 4 sera may be due to differences in the antigen concentrations used by the tests and/or to conformationrelated suboptimal accessibility of certain epitopes in the native $\mathrm{C} 100$ antigen. The strong reactivity of these 4 sera in the second-generation enzyme immunoassay can be accounted for by the use of a core antigen in EIA II. Two sera (tab. 2) reacted neither with the C100 antigen of the first-generation enzyme immunoassay, nor with $\mathrm{C} 100$ antigen fragments sp65/67, nor with core peptide sp75. Exclusive reactivity of these two sera in EIA II was demonstrated by a highly positive reaction with the $33 \mathrm{c}$ clone, which is different from the $\mathrm{C} 100$ antigen. The $33 \mathrm{c}$ antigen is used only in the second-generation EIA and, like the $\mathrm{C} 100$ antigen, is a non-structural protein. In three sera of the hepathopathy group a positive result with EIA I, EIA II and peptide EIA with sp65/57 was obtained, but the inhibition test was negative (data not shown). The negative results in the inhibition test in these cases can only be explained by the presence of antibodies to the 107 amino acid portion of the $\mathrm{C} 100$ antigen which does not overlap the inhibition antigen.

Parallel determinations of the titres of 42 sera that were reactive in both enzyme immunoassays showed that all but one serum yielded higher titres in EIA II (fig. 3). The average (median) titre of the 42 hepatitis $C$ virus positive sera was 17.4 for EIA I and 71.6 for EIA II. As an anti-hepatitis $C$ virus positive serum contains a mixture of antibodies to different epitopes of the hepatitis $\mathrm{C}$ virus polyprotein, the greater analytical sensitivity of EIA II is presumably the result of its greater antibody solid phase binding capabilities.

Neither the absorbance value nor the absorbance/ absorbance of cut off ratio is useful for determining the antibody concentration in a patient or blood donor serum. Thus, antibody titres greater than 16 al- 
ready result in maximal reactivity of the first-generation enzyme immunoassay, so that EIA I allows no differentiation of antibody concentrations beyond this titre (fig. 4). In the second-generation EIA, this saturation response does not occur until a titre greater than 64 is reached, so that EIA II is somewhat more amenable to determining a quantitative result from the absorbance of the undiluted sample.

In summary, it can be said that blood donor sera contain many sources of false positive reactions, including antibodies to yeasts (21), antibodies to the superoxide dismutase moiety of the fusion protein (25), and other cross-reacting antibodies $(26,27)$. These reactions are, for obvious reasons, relatively less frequent in populations at high risk of hepatitis $\mathrm{C}$ infection, such as haemophiliacs and liver disease patients. The significantly enhanced specificity of EIA II is presumably the result of using more highly purified recombinant proteins, as well as of the addition of the superoxide dismutase moiety of the fusion protein, along with $E$. coli and yeast lysate to sample diluents.

The enhanced sensitivity of EIA II would, however, appear to be even more important for blood donor screening than the improvement in specificity, since the EIA would then be capable of detecting and eliminating potentially infectious blood units that

\section{References}

1. Reesink, H. W. \& van der Poel, C. L. (1989) Blood transfusion and hepatitis: still a threat? Blut 58, 1-6.

2. Choo, Q.-L., Kuo, G., Weiner, A. J., Overby, L. R., Bradley, D. W. \& Hougthon, M. (1989) Isolation of a cDNA clone derived from a blood-borne Non-A, Non-B viral hepatitis genome. Science 244, 359-362.

3. Kuo, G., Choo, Q.-L., Alter, H. J., Gitnick, G. L., Redeker, A. G., Purcell, R. H., Miyamura, T., Dienstag, J. L., Alter, M. J., Stevens, C. E., Tegtmeier, G. E., Gonino, F., Colombo, M., Lee, W.-S., Kuo, C., Berger, K., Shuster, J. R., Oberby, L. R., Bradley, D. W. \& Houghton, M. (1989) An assay for circulating antibodies to a major etiology virus of human non-A, non-B hepatitis. Science 244, 362-364.

4. Choo, Q.-L., Weiner, A. J., Overby, L. R., Kuo, G. \& Houghton, M. (1990) Hepatitis $C$ virus: the major causative agent for viral non-A, non-B hepatitis. Brit. Med. Bull. 46, $423-441$

5. van der Poel, C. L., Lilie, P. N., Choo, Q.-L., Reesink, H. W., Leentvaar-Kuypers, A., Kuo, G. \& Houghton, M. (1989) Anti hepatitis C antibodies and Non-A, Non-B posttransfusion hepatitis in the Netherlands. Lancet II, 297298.

6. Esteban, J. I., Viladominu, L., Gonzalesz, A., Roget, M., Genesca, J., Esteband, R., Lopez-Talavera, J. C., Hernandez, J. M., Vargas, V., Buti, M., Guardia, J., Houghton, M., Choo, Q.-L. \& Kuo, G. (1989) Hepatitis C virus antibodies among risk groups in Spain. Lancet II, 294-297.

7. Roggendorf, M., Deinhardt, F., Rasshofer, R., Eberle, J., Hopf, U., Möller, B., Zachoval, R., Pape, G., Schramm, W., Rommel, F. (1989) Antibodies to hepatitis C virus. Lancet $I I, 324-325$. would otherwise be transfused. Several studies have demonstrated that specific detection of anti-hepatitis $\mathrm{C}$ virus antibodies $(14,23)$ is associated with infectiousness of the blood, i. e. the antibodies are indicative of chronic viral replication rather than of immunity. Disappearance of previously detected antihepatitis $\mathrm{C}$ virus antibodies can be considered as evidence that the disease has healed and/or that viral replication has been interrupted $(28,29)$.

The approach of choice for evaluating the safety of blood products and the patient's infectious status and prognosis therefore consists of the use of a diagnostic method that is capable of detecting different antihepatitis $C$ virus antibody specificities with maximum sensitivity and maximum specificity. The second-generation anti-hepatitis $C$ virus antibody enzyme immunoassay, which uses three distinct recombinant hepatitis $\mathrm{C}$ virus proteins and has been studied in this investigation, constitutes a significant advance in this respect. Nevertheless sera that are reactive in this EIA II should be confirmed by a defined (fully synthetic and/or recombinant) hepatitis $C$ virus peptide EIA and/or a multiantigen immunoblot assay (14).

\section{Acknowledgement}

We thank Prof. Dr. Eckard Lechler, Klinik I für Innere Medizin der Universität zu Köln, for sera of haemophilia patients.

8. Editorial (1990) Hepatitis C Virus Upstanding. Lancet $I$, $1431-1432$.

9. Runi, M. G., Colombo, M., Gringeri, A. \& Mannucci, P. M. (1990) High prevalence of antibodies to hepatitis C virus in multi-transfused hemophiliacs with normal transaminase levels. Ann. Intern. Med. 112, 379-380.

10. Makris, M., Preston, F. E., Triger, D. R., Underwood, J. C. E., Choo, Q.-L., Kuo, G. \& Hunghton, M. (1990) Hepatitis $\mathrm{C}$ antibody and chronic liver disease in haemophilia. Lancet $I, 1117-1119$.

11. Kühnl, P., Seidl, S., Stangel, W., Beyer, J., Sibrowski, W. \& Flik, J. (1989) Antibody to hepatitis C virus in German blood donors. Lancet $I I, 324$.

12. Sirchia, G., Bellobuono, A., Giovanetti, A. \& Marconi, M. (1989) Antibodies to hepatitis C virus in Italien blood donors. Lancet $I I, 397$.

13. Stevens, C. E., Taylor, P. E., Pindyck, J., Choo, Q.-L., Bradley, D. W., Kuo, G. \& Houghton, M. (1990) Epidemiology of hepatitis C virus. J. Am. Med. Ass. 263, 49-53.

14. van der Poel, C. L., Cuypers, H. T. M., Reesink, H. W., Weiner, A. J., Quans, S., Di Nello, R., van Boven, J. J. P., Winkel, I., Mulder-Felkerts, D., Exel-Oehlers, P. J., Schaasberg, W., Leent vaar Kuypers, A., Polito, A., Houghton, M. \& Lelie, P. N. (1991) Confirmation of hepatitis C virus infection by new four-antigen recombinant immunoblot assay. Lancet $I I, 317-319$.

15. Prohaska, W., Wolff, C., Lechler, E. \& Kleesiek, K. (1991) High rate of false positives in blood donor screening for hepatitis $\mathrm{c}$ virus. Cause for underestimation of virus transmission rate? Klin. Wochenschr. 69, 294-296. 
16. van der Poel, C. L., Reesink, H. W., Schassberg, W., Leentvaar-Kuypers, A., Bakker, E., Exl-Oehlers, P. J. \& Lelie, P. N. (1991) Infectivity of blood seropositive for hepatitis C virus antibodies. Lancet $I I, 558-560$.

17. Garson, J. A., Tedder, R. S., Briggs, M., Tuke, P., Glazerbrook, J. A., Trute, A., Parker, D., Barbara, J. A. J., Contreras, M. \& Aloysius, S. (1990) Detection of hepatitis $C$ viral sequences in blood donations by "nested" polymerase chain reaction and prediction of infectivity. Lancet $I, 1419-1422$.

18. Mc Farlande, J. G., Smith, H. M., Johnson, P. J., Bray, G. P., Vergani, D. \& Williams, R. (1990) Hepatitis C virus antibodies in chronic active hepatitis: pathogenetic factor or false-positive result? Lancet $I I, 754-757$.

19. Skidmore, Susan (1990) Recombinant immunoblot assay for hepatitis $C$ antibody. Lancet $I, 1346$.

20. Colombo, M., Runi, M. G., Mannucci, P. M. (1990) Specificity of hepatitis C antibody ELISA in patients with haemophilia. Lancet 1345.

21. Dawson, G. J., Sarin, V., Leung, T., Dere, S., Desoi, S., Casey, J., Rote, K., Robey, W. G., Boardway, K. A., Gutierrez, R. A., Peterson, D. A. \& Lesniewski, R. R. (1990) Alternate assay configurations for detection of anti HCV. Presentation at the VIIIth International Congress of Virolog, Berlin August 1990.

22. Menitove, J. E., Richards, W. A. \& Destree, M. (1990) Early US experience with anti-HCV kit in blood donors. Lancet II, 244-245.

23. Ebeling, F., Nakkarinen, R. \& Leikola, J. (1990) Recombinant immunoblot assay for hepatitis $\mathrm{C}$ virus antibody as predictor of infectivity. Lancet $I, 982$.
24. Colombo, M., Runi, M. G. \& Mannucci, P. M. (1990) Specificity of hepatitis $C$ antibody ELISA in patients with haemophilia. Lancet $I, 1345$.

25. Ikeda, Y., Toda, G., Hashimoto, N., Kurokana, K. (1990) Antibody to superoxide dismutase, autoimmune hepatitis, and antibody tests for hepatitis $C$ virus. Lancet $I, 1345-$ 1346.

26. Gray, J. J., Wregkitt, T. G., Friend, P. J., Wright, D. G. D., Sundareson, V. \& Calue, R. Y. (1990) Differentiation between specific and unspecific hepatitis $C$ antibodies in chronic liver disease. Lancet $I I, 609-610$.

27. Theilmann, L., Blazek, M., Goeser, T., Gmelin, K., Kommerell, B. \& Fiehn, W. (1990) False anti-HCV tests in rheumatoid arthritis. Lancet $I, 1346$.

28. Tremolada, F., Casarin, C., Tagger, A., Ribero, M. L., Realdi, G., Alberti, A. \& Ruol, A. (1991) Antibody to hepatitis $C$ virus in post transfusion hepatitis. Ann. Intern. Med. 114, 227-281.

29. Farci, P., Alter, H. J., Wong, D., Miller, R. H., Shih, J. W., Jett, B. \& Purcell, R. H. (1991) A long term study of hepatitis $C$ virus replication in non-A, non-B hepatitis. $N$. Engl. J. Med. 325, 58-104.

30. Kato, N., Yokosuka, O., Omata, M., Hosada, K. \& Ohto, M. (1990) Detection of hepatitis $C$ virus ribonucleic acid in the serum by amplification with polymerase chain reaction. J. Clin. Invest. 86, 1764-1767.

31. Mimms, L., Vallari, D., Ducharme, L., Holland, P., Kuramato, I. K. \& Zeldis, J. (1990) Specificity of anti-HCV ELISA assessed by reactivity to three immunodominant HCV regions. Lancet $I, 1590-1591$.

Dr. W. Prohaska

Institut für Laboratoriums- und

Transfusionsmedizin

Herzzentrum Nordrhein-Westfalen

Universitätsklinik der Ruhr-Universität Bochum

Georgstraße 11

W-4970 Bad Oeynhausen

Bundesrepublik Deutschland 